\title{
Strategies and tactics for local market making in the Temporary Staffing Industry
}

\begin{abstract}
This paper examines the increasing complexity of interactions between temporary staffing agencies and their client firms within the local labour market of Birmingham, UK. Temporary Staffing Agencies have been identified as active and influential agents in local, national and international labour markets. Their influence on local labour market functioning, national labour regulation and international regulatory frameworks is growing. Existing literature demonstrates the power of large multinational temporary staffing agencies in both established and emerging temporary staffing markets. Such analyses also contend that multinational agencies operate in very different ways to smaller independent 'back-street' temporary staffing agencies, with different types of clients and at different ends of the market. However, the research conducted in Birmingham, UK suggests that the reality is more complex. It is argued that there can be more subtle and intricate nuances of relevance to the temporary staffing industry in respect of the relationships that exist between large and small temporary staffing agencies, as well as between such agencies and their clients. We highlight how smaller agencies in Birmingham are utilising a variety of strategies and tactics to creatively 'bolt-on' to more formalised national agreements established by multinational agencies with their clients. Moreover, smaller agencies - in some instances - are able to exploit their knowledge of local labour markets to subvert, sabotage and / or infiltrate the activities of multinational agencies in increasingly astute ways. In turn, this generates a series of questions for understanding the nature of 'market making' associated with the temporary staffing industry more broadly.
\end{abstract}

Keywords: Temporary Staffing Industry; local labour markets, subversion; sabotage 


\section{Introduction}

This paper provides a number of new insights into the way in which the temporary staffing industry operates and the role and function of temporary staffing agencies in 'market-making' activities. In particular, through analysing the temporary staffing industry at a local level, rather than at a national or international level, the research - conducted in Birmingham, UK highlights a number of previously undocumented ways in which temporary staffing agencies may operate in the local labour market. Temporary staffing agencies (also known as temporary help firms or temporary work agencies) act as intermediaries between workers and employers. They facilitate the outsourcing of jobs to 'temps' (workers) on open-ended contracts, thus providing an alternative to direct employment. They are commonly used by employers to make quick alterations to employee numbers in response to fluctuations in demand, to cover short term absenteeism, when (non-firm-specific) expert skills are required, for seasonal agricultural work or unsociable shifts patterns, for example.

Temporary staffing agencies are increasingly integral to how public and private organisations recruit new employees, who gets employed and how. The emphasis in the UK on labour market flexibility has ensured that the country is the third largest market for temporary agency work and represents nine per cent of the global agency work market (International Confederation of Private Employment Agencies - CIETT, 2012). In 2010 there was an estimated 11,500 private employment agencies in the UK comprising of 17,000 different branches. The UK has the fourth largest number of agencies after China, Japan and the US (CIETT, 2012). In 2009 there were 95,865 people working directly for temporary staffing agencies in the UK and 880,000 temporary agency workers employed daily (CIETT, 2012). 
A variety of studies have considered the extent to which there are national variations in temporary staffing markets (for example, see Forde, 2001; Ward, 2003b on the UK, Peck and Theodore, 1998; 2001 on the US, Coe et al., 2008 on Eastern Europe, Coe et al., 2009a on Australia, Coe et al., 2009b on Sweden and Vosko, 2000 on Canada, Coe et al., 2011 for an overview of internationalisation strategies). Indeed, such work indicates how the activities of the largest multinational temporary staffing agencies - namely Manpower, Adecco, Kelly Services, Randstad, Vedior and Spherion - have influenced national and international regulation of temporary staffing and in doing so created conditions conducive to the growth of the industry (Kuptsch 2006; Gonos, 1997). For example, some of the larger temporary staffing agencies are being consulted as independent labour market experts by national governments and as such influencing the regulation and policy of national temporary staffing markets (Peck et al., 2005; Peck \& Theodore, 2002). They have also increased their functional integration into some of the world's largest firms (Forde, 2001; Ward, 2004).

Nevertheless, the prevailing focus on the market making activities of the largest temporary staffing agencies is surprising, especially in the UK, where the three largest agencies (Manpower, Adecco, Kelly Services) make up only 11.4 per cent of the market share. This is opposed to 72.3 per cent in France and 64.9 per cent in the Netherlands whose markets are equally mature (Peck et al., 2005). This figure attests to the overwhelming proportion of small, independent and locally operated agencies in the UK that have created a highly fragmented and competitive temporary staffing market (Ward, 2002). This fragmentation comparable only to the US where the largest three temporary staffing agencies have 11.9 per cent market share - creates a temporary staffing market in the UK in which multinational and 
independent agencies rub shoulders on the high street and compete for the same business and the same pool of labour at a local level.

As well as examining national variations in temporary staffing markets, a number of studies have also analysed the strategies and tactics of temporary staffing agencies as they compete for the same clients and pools of workers in local labour markets (see Ward 2003a; 2005 on Manchester (UK); Peck \& Theodore, 2001 on Chicago (US); Gottfried and Fasenfest, 2001 on Detroit (US); Forde’s (2001) work on Leeds and Telford (UK) and Theodore and Peck's 2012 comparative analysis of temping at a metropolitan scale (US)). However, this paper moves beyond such analyses to provide a number of new and critically important insights into the strategies and tactics that are being used by temporary staffing agencies to compete shoulder to shoulder in a thriving and competitive temporary staffing market - Birmingham, UK. In particular, it highlights a number of key ways in which smaller temporary staffing agencies exploit opportunities that are available within local markets to enhance their market making ability. These include: i) 'bolting-on' to wider agreements made between larger agencies (those with multiple branches across the UK or internationally) and their clients which allows smaller temporary staffing agencies to increase their own functional integration in client firms and; ii) smaller agencies subverting or sabotaging agreements between larger agencies and their client firms through the strength of their own relationships with local actors. In so doing, we identify how such activities also re-shape the ways in which larger agencies seek to maintain and develop their own position within local labour markets.

Section Two of the paper develops a detailed and critical assessment of the recent literature on temporary staffing agencies. Section Three subsequently presents the methods used and describes the relevance and importance of the case study location (Birmingham, UK). In 
Section Four we present our key findings which examine in more detail the strategies and tactics of temporary staffing agencies in Birmingham and their local competitive dynamics which - in some instances - includes subverting national agreements, bolting-on to wider agreements and exploiting the strength of local relationships. Section Five sets out our conclusions and the broader implications of our research for understanding the nature of 'market making' in the context of the temporary staffing industry.

\section{The Temporary Staffing Industry: local variability}

This section initially examines the growth and influence of the temporary staffing industry and the market-making activities of larger agencies. It subsequently introduces the importance of the local labour market as a key scale for understanding the temporary staffing industry. It is argued that analysing the local temporary staffing industry necessitates an appreciation of the different types of agencies operating locally, including the importance of their size. This informs a call for further work on investigating the strategies and tactics that are being used by different-sized agencies to market-make in the context of local labour markets.

(i) Growth and influence of the temporary staffing industry and market-making activities

The growth and geographical spread of the temporary staffing industry over time has varied between countries and can depend on national regulatory regimes, as well as the degree of

reliance on temporary workers (Table 1). Historically the largest markets for temporary staffing have been in the US and the UK. Indeed, as the larger US agencies began to expand 
geographically from their heartlands they were quick to colonise the UK market and subsequently the rest of Europe.

However, the growth and geographical expansion of the largest multinational temporary staffing agencies is only part of the story. During the 1990s, the UK labour market began to see a "burgeoning number of small, locally operated and often 'back-street temp services"” (Peck \& Theodore, 2001:476). Initially with a focus on placing women in office jobs and men in construction, these agencies soon began to diversify into other sectors and occupations so that by the late 1990's the UK temporary staffing industry had experienced a rapid expansion in both multinational and domestic agencies across a wide range of locations and sectors.

Other countries in Europe such as France, Germany and the Scandinavian nations have been more cautious about the liberalisation of employment regulations compared to the UK and as such have seen a slower rise of temporary staffing agencies. Nonetheless, the temporary staffing industry in these countries has been growing quickly since the early 1990s (Peck et al., 2005). The last decade has witnessed an acceleration in the legalisation of agencies and significant re-regulation favourable to temporary staffing agencies outside the US and UK heartlands and across most countries. Moreover, as policies of labour market deregulation spread through many OECD and transition countries, the subsequent increase in flexibility amongst business has allowed temporary staffing agencies to capitalise on the swell of temporary staff. Indeed, the growth of temporary staffing agencies has closely followed this wider trend of deregulation, so much so that they have now become a major new institutional presence in liberalising economies, registering exponential growth in the wake of liberalisation (Peck et al., 2005). 
Peck et al. (2005:10) argue that the expansion of temporary staffing agencies is greatest in "historically well-regulated but now actively liberalising labour markets" (emphasis in original) which include, but are not restricted to, Italy, Germany, Japan and Spain; they call these areas 'virgin territory'. This has resulted in a "phenomenal increase of the [employment agency] industry over the last two decades” (McDowell et al., 2008:751). Nevertheless, the market making role of temporary staffing agencies can differ within different regulatory regimes.

Benner et al. (2007) have argued that there is a spectrum along which labour market intermediaries - such as temporary staffing agencies - may shape the characteristics and dynamics of the labour market. They refer to these activities as 'market meeting', 'market moulding' and 'market making'. Market meeting refers to activities which simply match workers with employers to fill available jobs. Market moulding activities refer to those which go beyond short-term match-making to improve the career opportunities for temps. Market making refers to the activities of temporary staffing agencies which alter the quality and distribution of jobs and therefore allow such agencies to play a critical role in structuring the characteristics of jobs themselves. It is therefore in terms of market making that activities by large temporary staffing agencies such as international lobbying, advising governments and integration into employers can be placed (Peck and Theodore, 2002).

\section{TABLE ONE HERE}

(ii) The local labour market as a key scale for understanding the temporary staffing industry 
An important turning point in the literature on temporary agency work - and which helps to contextualise processes of market making - relates to the emergence of the agency perspective (Coe et al., 2010). The agency perspective argues that due to the growth and prevalence of temporary staffing agencies, research on the temporary staffing industry should focus on the activities of agencies themselves and what impact they have on labour market functioning, employment norms and employment regulation. Prior to this, literature on temporary agency work had largely examined these issues through either a worker or firm perspective. Research based on the worker perspective examined the groups in society most likely to be employed via an agency (Vosko, 2000), why workers used agencies (Van Breugel, et al., 2005; Bergstrom \& Storrie, 2003; Lenz, 1996; Purcell et al., 2004) and the experiences of agency workers (Gottfried, 1991, 1992). Research based on the firm perspective explored why firms used temporary staffing agencies, how different sectors used temporary staffing agencies to achieve numerical and functional flexibility (Befort, 2003, Forde, 2001; Kalleberg, 2000) and the ways temporary staffing agencies have changed staffing strategies in firms.

Nevertheless, whilst existing research on temporary staffing agencies from an agency, worker and firm perspective has provided valuable insights into the evolving nature of the industry, there has been less focus on the activities and competitive dynamics between large multinational agencies and smaller independent temporary staffing agencies. Equally, there has also been less emphasis on the role of temporary staffing agencies (both large and small) in the local labour market.

The conceptual category of the 'local labour market' is therefore important in that the role and function of temporary staffing agencies will vary from local context to local context. 
Debates within labour geography have long discussed the geographical unevenness and variability in labour market phenomena. Early segmentation theory explored the notion of different groups of workers operating in what appeared to be "different labour markets, with different working conditions, different promotional opportunities, different wages, and different market institutions” (Reich, et al., 1973:359). Academics argued that the segmentation of the labour market into different subgroups was due to political-economic forces and was achieved through different segmentation processes (Reich et al., 1973). Indeed, duel labour market theory emerged as a means of explaining the experiences of different groups within 'primary’ and ‘secondary’ labour markets (Doeringer \& Piore, 1971; Bosanquet \& Doeringer, 1973).

Such debates on segmentation and labour market structuring began to move analysis away from orthodox economic theory and recognised instead that labour markets are socially structured and institutionally mediated. However, segmentation theory was relatively silent on the question of geographic variability and showed limited sensitivity to the role of geography in labour market variation (Peck, 1996). Massey’s (1984) work on the spatial divisions of labour changed this and became one of the most influential analyses on the inherently spatial nature of employment and production. It highlighted how it is possible for different localities to be associated with different stages of the production process and with the spatial division of labour becoming an intra-sectoral one, with places being known for who is employed there in certain stages of the production process rather than what they produce (Clarke et al., 1986).

Peck (1996) has used a reinterpretation of the local labour market to bring together the ideas of segmentation and localisation. As such, Peck's theoretical analysis of the local labour 
market is used in this paper as a means of incorporating notions of social regulation in labour market functioning and local variation within the temporary staffing industry. In so doing, it highlights the ways that temporary staffing agencies may contribute to local variations in segmentation and employment. Nonetheless, we cannot ignore the connectedness of many larger temporary staffing agencies to wider global economic networks (Ward, 2003a), as well as the potential for local inflection of extra-local agreements or influences. Therefore, in order to understand the reciprocal relationship between temporary staffing agencies, local economic geographies and wider networks we must recognise each as part of a local labour market that is dynamic and socially produced (Peck, 1996). It also requires an analysis of the interactions which may impact the role of agencies locally and how this can affect their role as market makers or marginal players in the local labour market.

Furthermore, Peck (1996: 87) has argued that "if labour processes are shaped by their institutional context, then geographic variability in contextual factors ... is likely to be associated with spatial unevenness in labour markets" and therefore "[w]hat matters is not simply that institutions have effects, but what effects they have, when, and where”. For these reasons, we argue that the temporary staffing industry is an inherently local industry. Whilst the geographical reach of elite search agencies and temporary staffing agencies can vary noticeably, with professional recruitment frequently operating on an international scale, amongst temporary staffing labour markets "most of their transactions are local ones connecting local job seekers to local employers” (Peck et al., 2005). Despite the increasing mobility of capital and the fundamental advances in business connectivity led by technological advancements, “[t]emporary staffing remains a stubbornly local industry” (Coe et al., 2010, 1065). This is because temporary staffing agencies are fundamentally tied to local labour markets in ways that other factions of capital are not; their dependence on place- 
bound labour as their trading commodity has the effect of anchoring or 'territorially embedding' temporary staffing agencies to areas where there is a sufficient amount of workers with the skills they require (Coe et al., 2009c). Although larger international agencies may capitalise on new foreign markets, they still "need some local people too, because every market is different in terms of labour-market rules, and customs” (Investment Analyst quoted in Peck et al., 2005, 12).

(iii) Strategies and tactics for market making in local labour markets

Geographic variations in labour markets may create temporary staffing markets with specific characteristics relating to the institutional mix of agencies in the area, the evolution of the temporary staffing industry locally and - importantly - the (spatial) strategies and tactics of agencies. As such, there is a need to understand how agencies compete locally for the same labour pools and the same client firms. In turn, this necessitates an appreciation of the differences between agencies that co-exist on the same high-street but that have vastly different scope and presence locally, nationally and internationally.

Size is an important factor influencing the strategies and tactics that temporary staffing agencies employ. There remains a shortage in the existing literature of attempts to describe the specific characteristics of different sized agencies. Nonetheless, the importance of the size of agency is often referred to. For example, in their study of hiring halls in Chicago, Peck and Theodore (1998, 2001) differentiate between "national and multinational agencies like Manpower, Kelly and Olsten [sic]" and the "small, locally-operated and often 'back-street' temp services” $(2001,476)$. Their research proffers the importance of size as a factor for local operations. For example, they argue that the larger corporate agencies are moving into higher 
skilled occupations within the industry and developing long-term, contract based relationships with clients. In turn, these accord them a more integrated position within the client firm and as such involves a restructuring upwards into the high-end industrial sectors. On the other hand, many of the locally-operated agencies gain the majority of their business amongst low-skilled occupations at the 'low-end' of the light industrial sector. Here, contracts are uncommon, relationships with clients are insecure and agencies compete under fiercely competitive and price sensitive conditions. In contrast, these smaller agencies are restructuring downwards (Peck \& Theodore, 1998, 2001). Peck and Theodore argue (1998) that the temporary staffing industry is polarising between these two types of agencies with both groups demonstrating different strategies and tactics to win different types of clients.

Therefore, understanding the complexities of agency size and how this affects the competitive strategies of agencies within the local labour market is particularly important, and especially within the UK context. In the UK, the emphasis on labour market flexibility has ensured that the country is the third largest market for temporary agency work in the world (CIETT, 2012). It generates an estimated value of £24.7bn, 90 per cent of which (£22bn) is comprised of turnover from the temporary staffing sector (REC, 2011). However, in the UK there is a very low 'branch to agency' ratio for temporary staffing agencies, indicating a proliferation of small (often single site) agencies which operate alongside branches of the larger temporary staffing agencies on the high-street (Ward, 2003b, 2002).

Consequently, the host of smaller independent agencies creates a more chaotic and competitive market for temporary staffing “quite unlike any other temporary staffing industry in the 'developed' world” (Ward, 2002, 6), the intricacies of which we would suggest still need to be fully explored, particularly at a metropolitan level and in relation to specific cities. 
This paper therefore seeks to respond to this gap in knowledge in order to consider the intricacies of the social and contractual interactions between different temporary staffing agencies; how these are articulated at a local level; and the hierarchies emerging between agencies which suggest that there are ways in which smaller agencies can engage in market making.

\section{Methodology}

In order to explore strategies and tactics for local market making, a suitable focus for the research was required. To this end, an initial decision was made to concentrate on temporary staffing agencies which place temps in low-skilled industrial jobs such as warehouse and production operatives, seasonal agricultural workers, as well as various types of drivers including forklift truck, $\mathrm{HGV}$ and transit drivers. These sectors were chosen for a number of reasons. First, the Recruitment and Employment Confederation (REC) estimated that in 2010/2011 over a million placements were made by temporary staffing agencies in the UK, with 'industrial/blue collar' placements making up the largest proportion, constituting 24 per cent of all placements (REC, 2011). In addition, Coe et al. (2009a, 67) have identified "administrative clerical and support staff and blue-collar workers as... the core occupational niches of the temporary staffing industry”. Third, when conducting the pilot study for this research we found that the vast majority of agencies which place blue-collar workers in industrial jobs also place drivers. These areas of industry overlap considerably and clients that require temps for warehouse and production jobs concurrently required agency temps for driving, delivery and logistics operations. As such, this research focuses specifically on such agencies because they exhibit the low-margin high-volume business strategy most strongly. 
With regards to the selection of an appropriate case study area, Birmingham - located in the West Midlands - and which is the second largest city in terms of population in the UK - was deemed to be an excellent case study location for studying temporary staffing agencies specialising in low-skilled industrial/blue collar and driving placements. Its industrial history is reflected in the fact that temporary staffing agencies in the city are very active in occupational sectors such as secretarial/clerical, customer service, industrial/blue collar, technical/engineering, driving and construction (REC, 2006). For example, the REC Census (2011) highlighted that within the Midlands 31 per cent of agencies recruit and place workers in the industrial/blue collar sector compared with a national average of 24 per cent. Additionally, 23 per cent of agencies in the Midlands recruit for driving occupations compared with only 17 per cent nationally.

Birmingham is also useful for examining the competitive strategies for market making between different sized agencies at the local level given the fact that there is a high level of fragmentation in the temporary staffing industry. In this respect, the 2006 REC census identified that 64 per cent of agencies in the Midlands were single-site businesses, 11 per cent were head offices and 25 per cent were part of a larger network. ${ }^{1}$ This reflects the UKs TSI more broadly and highlights the large proportion of small independent agencies in the market place competing for the same business as larger agencies. The Census also identified that within the Midlands there are a higher percentage of agencies that employ 2-5 people (57 per cent) compared to the national average (52 per cent) and only 12 per cent of agencies employed over 11 people compared with the national average of 16 per cent. This demonstrates that within the Midlands there are a larger proportion of small (single-site) agencies (with between 2-5 employees) compared to the rest of the country.

\footnotetext{
${ }^{1}$ In this instance the REC describes single-site agencies as those which consist of just one office, head offices are the main offices for agencies with more than one office. Being part of a larger network refers to an agency office which is incorporated into a larger branch network but is not the head office of that agency.
} 
In addition, Birmingham has a comparatively high unemployment rate at 5.9 per cent, which is the second highest claimant unemployment rate of the 'core cities' (the eight largest cities outside of London) in the UK and significantly above the core city average of $4.5 \%$ (Birmingham City Council, 2015). This means there is a large surplus of available labour in Birmingham. As such, temporary staffing agencies in the city have the client base and the labour pool to provide thriving conditions for growth in the city.

The Birmingham case study encapsulated all locations within the Birmingham (B) postcode, including the forty wards in the political boundary of Birmingham and the wider Birmingham conurbation including Solihull, Sutton Coldfield, West Bromwich, Oldbury, Smethwick and Cotteridge. Use of the FAME database ${ }^{2}$ subsequently identified 974 temporary staffing agencies (SIC code N78.20) in the West Midlands. Further research and data cleaning identified that 87 of these agencies recruited for the industrial/blue collar and driving sector in the B postcode area. This represents 26.6 per cent of all the agencies in the B-postcode area. This figure sits between the Midlands average for industrial and driving agencies presented in the REC Census but is still above the national average on both counts.

Subsequently 65 semi-structured interviews were conducted with agency managers/owners (40 interviews across agencies of varying sizes) and their client firms (13 interviews through a 'matched pairs' sampling strategy), as well as a number of industry 'experts' (12 interviews). Themes that were explored included the effect of local economic and geographic

\footnotetext{
${ }^{2}$ FAME - Financial Analysis Made Easy - is a financial database of 7 million companies in the UK and Ireland. It used Companies House data and contains detailed financial, descriptive and ownership information for companies. The database can be searched using a variety of criteria. For this research post code and SIC code criteria were used to stratify the data.
} 
characteristics on the activities of temporary staffing agencies, the importance of client relationships and the impact of size on the activities of temporary staffing agencies.

Secondary data was also collected through industry reports such as the Staffing Industry Analysis (SIA) and via debates on internet forums which included The LinkedIn Forum for recruitment UK, UK Recruiter Forum, Birmingham (UK) Recruiters Network, Key Personnel HR Forum and Recruit eForum. This was particularly useful for staying abreast of developments in the local recruitment industry as well as posing questions that emerged during the research.

Subsequently - and following the interviews - a process of open coding, axial coding and iterative theory building was used to analyse the interview transcripts. Open coding consisted of scrutinising all interview transcripts in order to break up the data and produce concepts that later became themes, such as client-agency relationships and issues of centralisation, contractualisation and local resistance. Axial coding was then used to put the data back together in new ways by making connections between such categories, integrating them and identifying the relationships between them - for example, the linkages between national and local agreements. This was an iterative process; the aim was not to 'add up' the insights of the different transcripts but to combine them in the construction of empirically grounded theories which best explained the data.

Finally, with reference to the importance of economic context for the research, the interviews took place between March 2011 and August 2012. In this respect, it is relevant to point out that whilst the temporary staffing industry in the UK and beyond had experienced a decline during the economic recession that had commenced in 2008, the temporary staffing industry 
in the UK had experienced a return to growth since the beginning of 2010 and had recovered much of the ground lost during the recession (CIETT, 2012). Indeed, more recent reports in the UK have identified that non-regular work has increased, and is being encouraged as a solution to problems of high unemployment (Slater, 2011).

\section{Strategies and tactics for local market making: the case of Birmingham}

Before exploring processes of market making by smaller temporary staffing agencies in Birmingham - and the subsequent implications arising for the functioning of local labour markets - it is important to discuss the characteristics and particularities of the temporary staffing industry in Birmingham itself.

(i) The particularities of Birmingham's temporary staffing industry

At the time of the research, there were four temporary staffing agencies in Birmingham that were perceived by interviewees to dominate the industrial and driving market. Together they included The Best Connection, First Personnel, Pertemps and Blue Arrow. The research revealed that many of the smaller independent agencies in the city were established by people who started their careers at these four key agencies. As such, the regional dominance of these four agencies gave rise to a new wave of smaller, local independent agencies from the late 1990s onwards. The prevalence of these agencies in the local area also meant that it was difficult to identify any interviewees that didn't have some connection - either as previous employees; in respect of the sharing of clients; or in terms of winning / losing contracts - to one of these agencies. This gave Birmingham a distinct identity as a temporary staffing market due to the fact that three of the four key agencies in the city were established locally. 
Moreover, given that the three largest multinational agencies in the city - Adecco, Manpower and Kelly Services - were rarely considered as major competitors by participants, this illustrated how Birmingham's temporary staffing industry differed from other regions or cities because of the unique way the industry had evolved, the perceived prevalence of longestablished local agencies and the specific social relationships between different agencies that had affected this evolution. Indeed, the prevalence of low-skilled, industrial, driving and other blue collar jobs in Birmingham's temporary staffing industry differs from other strong knowledge based economies such as Manchester and London due to a higher proportion of agencies that specialise in these sectors and the specific characteristics and inherent competition which underpins the high-volume low-margin strategies of temporary staffing agencies in the light industrial and logistics sectors (Peck \& Theodore, 1998). This contrasts with the low-volume high-margin business model of temporary staffing agencies recruiting for more skilled positions in clerical, admin, IT, accountancy and law firms such that Ward (2005, 2003a), for example, has highlighted in Manchester. Coupled with the social relations, interactions and networks which underpin the industry, these factors are influential in shaping a highly complex, interrelated and volatile market for Birmingham's temporary staffing industry.

\section{(ii) Competitive chaos and strategies for market making}

Having discussed the particularities of Birmingham, the rest of this section explores the 'competitive chaos' that has followed the establishment of so many smaller local independent temporary staffing agencies in the UK, and which has been highly evident in Birmingham following the departure of personnel from The Best Connection, First Personnel, Pertemps 
and Blue Arrow to start up their own agencies. In many accounts, an overall decline in agency margins has been explained as the primary result of market saturation (Peck and Theodore, 2002). However, we contend that smaller temporary staffing agencies are not just driving agency margins down; crucially they are also changing the nature of competition amongst larger multinational agencies. Through their relationships with local client stakeholders and their interaction with one another, smaller local independent temporary staffing agencies are forcing multinational agencies to develop new tactics to compete for business within the UK temporary staffing market. In this way smaller independent agencies are making markets for temporary staffing in new ways.

Indeed, the research conducted in Birmingham identified that agencies of varying sizes were using new and often quite different tactics to win business and place temps within the local labour market compared to those previously identified. In section two of the paper we noted the importance of temporary staffing agency activity, such as international lobbying and advising governments, as well as the functional integration of many temporary staffing agencies into some of the larger client firms. However, here we suggest that a number of other mechanisms that have been less recognised to date are also of critical importance for how the temporary staffing industry operates, and how temporary staffing agencies make markets. First, it will be illustrated how market making amongst smaller agencies particularly relates to their relationships with other agencies - and over and beyond their relationship with client firms. In particular, smaller agencies are finding ways to 'bolt-on' to wider agreements between large agencies and clients firms as a means of creating more secure positions for themselves within volatile temporary staffing markets. Second, we discuss the importance of local relationships in terms of the focus of market making and how smaller agencies are using strong social relations with local client branches to subvert wider national agreements 
between these same clients and larger agencies. As such, in the following two sections we present new insights into the ways in which smaller agencies compete to carve-out space for themselves within the UK temporary staffing market. These forms of market making are inherently local and rely on social relationships and co-operation amongst different sized agencies

\section{i) Bolting-on to wider agreements}

In this section we discuss how smaller agencies, often those with only one local branch or with just a few branches in a locally-specific region, are able to become part of more formalised agreements between larger agencies and client firms. Instead of secure, contractualised and less chaotic businesses being the reserve of larger agencies at the 'topend' of the market - and as suggested in the existing literature - smaller agencies are finding ways of bolting on to these restructuring processes in order to move up the market into larger client firms.

Previous studies have found that larger agencies with multiple national or international branches are able to create demand for their services by increasing their functional integration into large corporate firms (Ward, 2003a, 2003b, 2004; Forde, 2001). This is frequently undertaken through the negotiation of 'national agreements' or 'master vendor' agreements with client firms, meaning one agency will supply that client in all locations around a particular country (these agreements can extend to the supply of personnel in all countries if it is a global agreement). However, our research identified that smaller agencies - and even those with only one branch - are also able to become part of wider national agreements 
between larger agencies and client firms. They do this by bolting-on to these wider agreements and establishing relationships with larger agencies as opposed to the clients themselves. This was a common phenomenon in Birmingham but to date has not widely been recognised elsewhere and not explored in any real depth.

Bolting-on to the functional integration of larger agencies was being undertaken in two main ways in Birmingham. First, smaller agencies were able to supply clients via a second-tier agreement. This involved small independent agencies, frequently those with only one branch, developing a relationship with a larger national or multinational temporary staffing agency. The smaller agencies supplied the same clients indirectly through the national/multinational agency. This allows the larger agency to remain the sole supplier to the client (i.e. the only agency the client deals with directly) but ensures that large orders for temps will always be filled by the 'backup' smaller second-tier agencies (see Figure 1). This was discussed by the Managing Director (MD) of a large national temporary staffing agency, who explained their master vendor agreement and their reliance on a back-up of second tier agencies:

[Our agency] tend to work under master vend which means we say to the client "we can give you the platform and the infrastructure of managing your national supply, (but) please be aware we expect to fill $65-70 \%$ of it ourselves... and we will (then) manage certain second-tier relationships” (Managing Director, large national agency, 2012). 


\section{FIGURE 1 HERE}

The second way in which smaller agencies can bolt-on to wider / more formal agreements is through a neutral vendor. Again this was a common occurrence in Birmingham. However, this is also a growing issue in the UK more widely but has not, as of yet, been extensively discussed in the existing literature and which arguably warrants further attention. A neutral vendor is an independent organisation employed by the client firm to procure supplying agencies. The prevalence of neutral vendors across the UK is growing with companies using them to reduce costs, create standardisation across the supply chain and introduce transparency of margins, thus increasing competition amongst supplying agencies (see Figure 2). Major neutral vendors operating across the UK include Ethica, Rullion, Meridian, Datum, and de Poel, to name a few. The increasing use of neutral vendors across the UK therefore makes these findings significant to temporary staffing markets in all major cities in which neutral vendors operate. 


\section{FIGURE 2 HERE}

Under these two arrangements the master agency or neutral vendor, in effect, assumes the position of 'client company' for the second-tier of agencies. In some cases our research revealed that smaller temporary staffing agencies were happy to receive a large proportion of their business as a second-tier agency:

...we supply three or four different agencies with drivers. ... Since 2003/2004 we have supplied to Asda via another agency and to the NHS via another agency. There are probably six or seven [clients] that we have supplied to across different areas that all have this one big agreement. It's about treating them [the master agency] as a client. (Regional Manager: small temporary staffing agency, 2012).

It is reliable business [second-tiering].....we supply drivers to Argos, its low margin about $£ 2.00$ an hour but it’s reliable. ...we can make enough money second-tiering to Argos on just that account alone. If we forgot everything else and just worked on second-tiering to Argos we could get 20 to 30 guys in there a week, just secondtiering, which would pay for us all here (Owner, small temporary staffing agency, 2012).

In this way, some of the smaller agencies that are unable to supply large volumes of temps due to their size can benefit from the stability associated with the contractual agreements between larger clients and temporary staffing agencies by becoming a second-tier agency. As such, the market insecurity associated with restructuring downwards (Peck \& Theodore, 1998, 2001) experienced by smaller agencies - as a result of the dependence on ad hoc supply and 
the informal client-agency relationship - are mitigated by tapping into the regular, secure and formal arrangements between master agencies and large scale clients. This finding makes an important contribution to the current understanding of these second-tier relationships. For example, Ward (2003a:25) argues that in Manchester, second-tier agencies are happy to embark on these agreements in order to "take advantage of the inability of [their] competitors”. However, the research in Birmingham illustrates that the reality may be more subtle than this. In Birmingham, the contractual stability provided by master/neutral vendors and national agreements and the subsequent second-tier arrangements are attractive to agencies which may otherwise have to rely on more informal and insecure business. This means that many of the smaller agencies are dealing with larger agencies as if they were their clients, not competitors, and by doing so they make their own position in the market more secure, reliable and regular.

Therefore, a key point which emerges - and which has a wider applicability - is that only by examining the dynamics of the relationships between temporary staffing agencies can we understand why the temporary staffing industry is structured as it is and why some agencies are willing to enter into second-tier arrangements with their competitors. Such arrangements do not just provide temporary staffing agencies with an opportunity to 'out-do' competitors, but can instead provide a structural framework through which smaller temporary staffing agencies can access larger client firms that they may otherwise not have been able to work with. These findings highlight the importance of local relationships between agencies which can be driven by competition, but also by a desire for smaller agencies to create more secure places for themselves in temporary staffing markets. This adds to our current understanding of market making amongst agencies other than those with national and multinational reach. 
When smaller agencies negotiate second-tier relationships with neutral and master vendors at the local level, the local labour market acts as a site in which wider national agreements can be accessed by smaller temporary staffing agencies. These smaller agencies do not necessarily have the infrastructure or branch networks capable of developing the agreements themselves, yet their inclusion into secure, contractualised relationships with large clients is possible via the relationships they develop locally with larger agencies. In so doing, such temporary staffing agencies are moving beyond a 'no frills' approach to temporary staffing involving the supply of minimally processed labour as suggested in the existing literature (for example, see Peck and Theodore, 1998, 2002; Parker, 1994). Instead, our research demonstrates that they are frequently working with the same clients via second-tier agreements with large temporary staffing agencies. Thus the findings from Birmingham importantly highlight how smaller temporary staffing agencies can employ local tactics which allow them secure, formal business with the largest clients. In this way they are also restructuring upwards alongside their larger counterparts. Moreover, small agencies form an important element of the agreements between larger agencies and their clients which rely on a cohort of smaller agencies to ensure the fulfilment of national agreements. As such, this also tells us more about the ways in which larger temporary staffing agencies are supplying clients and securing their position as an integral feature of some organisations.

\section{iv) Local subversion and sabotage}

A second key finding that arose from the research relates to the ways in which smaller temporary staffing agencies utilised subversive tactics in order to undercut larger agencies and compete for the same business. This was a frequent and relatively common occurrence in Birmingham; however many of the larger agencies that were interviewed also discussed how 
this was happening in their other branch locations across the UK. Ward (2003a) has argued that at the low-end of the temporary staffing industry (for example, the low-skilled clerical and light industrial sectors), there are two forms of relations between temporary staffing agencies and client firms; formal contractual relations that occur with high volume placements and more informal relations built on trust which are prevalent when supply is just for 'ones and twos'. However, the findings from Birmingham suggest that there are variations amongst these two types of relations. One of the most common ways informal trust-based relationships can become intertwined with formal contractual relations is for a client to refuse to adhere to a national or master vendor agreement. Often these master and neutral vendor agreements are initiated by central Human Resources (HR) and/or procurement departments in the client firm. However, individual client sites - for example, regional warehouses and factories, can 'break rank' and may continue to work with small independent agencies outside of the national or master/neutral vendor agreement. In the research conducted in Birmingham we found that in the vast majority of cases, this happens when line managers in local client sites have developed strong working relationships with small independent agencies prior to the implementation of the wider (national/master/neutral) agreement. For example:

The other problem with the recruitment industry is; because there is a lot of ownermanaged businesses there is an awful lot of very localised cosy relationships.... and some of the reasons why people purchase from a certain agency are not necessarily in the company's best interests but they may be in the individual's best interests. So there is a lot of that goes on as well. So, centrally a company may take the view, in HR and Procurement, this is what we want to do and there may be local resistance; there quite often is: ‘No, no, no, I have always used Bob from Wolverhampton, we couldn’t run our operation without Bob!’ (CEO, national client firm, 2012). 
Depending on the strength of the 'localised' relationship between the line manager in the warehouse (for example) and the small independent agencies, it is possible that actors within the client firm can resist decisions made by central departments. Many of the small temporary staffing agencies who were interviewed in Birmingham could recount times when the line manager in the client firm they were working with had said; "Oh I know we are on a national agreement but we are going to ignore it” (Owner, single-site agency, 2011). In this way, a number of small independent agencies still benefited from the strength of their existing relationships with the client because they could maintain business with little change in margins while others were consigned to the terms and conditions of the wider agreement. This type of situation was also prevalent under neutral vendor agreements where the strength of relationships between line managers in local client sites and the small independent agencies meant that a chaotic and unruly process of recruitment - that the neutral vendor agreement was set up to control - continued.

There was also evidence which suggested that as well as resisting wider formal agreements, some line managers in local client sites and small independent agencies would cooperate in order to sabotage these types of agreements with the aim of overthrowing larger agencies. For example:

They [the line manager] play the game, and they will say to their incumbent agency; 'I am going to make a call to you in two days' time and I am going to want six people and I want them to be that, that etc. Get them lined up!' What they then do is go to the agency they have been told to go to, they call two hours before the deadline and tell them; 'I want six people’ and obviously they say; 'I’m sorry we can’t get you them'. 
The line manager then phones their manager to say; ‘they can’t do it, I have called my local person, they can get me six people, all experienced, all know what they are doing, I told you we shouldn't have changed from them, what do you want? Do you want the lorry to stay here empty, or do you want it filled?' The manager says; 'oh, go on then use them'.... (Managing Director, large national agency, 2012).

As this demonstrates, the resistance and sabotage of wider agreements by line managers and local independent agencies can allow these actors to re-shape agreements between the client and the larger agency. Again, this is a key point which has not widely been recognised to date. Whilst in some cases resistance may lead to an informal and often uncontrollable recruitment process as demonstrated in the first quotation above, what this tactic of sabotage often aims to do is to gain formal permission to use the existing incumbent by orchestrating the failure of the agency assigned by the wider agreement. Not only does this allow agencies that have a strong relationship with the line manager to maintain business with their client, but it formalises their role as a supplier, without them having to 'go around the back door' and supply informally.

Moreover, the research identified that these informal acts of resistance can permanently influence the formal procedures undertaken by the agency controlling the wider agreement. For example, the Managing Director of a large national agency explained that winning the wider agreement was the 'easy part' but rolling this out to local client sites was much more difficult.

The biggest cultural issue we see is when companies decide to take the decision making power away from line managers and give it to procurement. ...it becomes one 
of the biggest obstacles, forget making your paperwork and invoicing look how it is meant to look, forget consistency and compliance, the biggest obstacle when we take over a new contract is changing the hearts and minds of the end users. That is the biggest challenge we face. ... We have an implementation team go through that process... they assume because someone gives an order from on-high everybody will do as they are told and they don't. ... You get it all the time! We face it every time we implement a new contract, every time (Managing Director, large national agency, 2012).

In addition, the interviewee also highlighted how they had 95 branches in total across the UK, and that one of the biggest challenges related to the implementation of new national agreements in local sites, of 'winning hearts and minds'. This was deemed to be an obstacle 'every time [they] implement a new contract'. All of this therefore highlights the fact that informal relationships and the resistance they encourage are changing and reshaping the ways in which formal agreements are organised and implemented in the temporary staffing industry across the UK. In essence, the process of market making is increasingly multi-faceted and constantly evolving and that the interactions and relationships which develop between agencies and client firms are complex.

Contrary to existing research which suggests smaller agencies are operating at the lower end of the market and larger temporary staffing agencies at the upper end, many small agencies in Birmingham are thus willing to accept subcontracting and second-tier agreements with larger competitors as a way of mitigating the risks of other less secure business at the lower end of the market. Further to this, the introduction of third party organisations, such as neutral vendors, into the temporary staffing industry has changed the structure of the industry 
allowing smaller agencies to work on a national basis with large-scale users and clients they may not otherwise have been able to. Despite these routes into more secure business with larger clients, local relationships between temporary staffing agencies and clients can lead to the sabotaging of formal agreements. In turn, this can bring new forms of chaos and competition into the temporary staffing industry given that such relationships can socially regulate the temporary staffing industry in locally specific ways - and as exemplified in the context of the Birmingham case study.

\section{Conclusion}

In this paper we have demonstrated how the local labour market can be an important arena in which new opportunities for business development and market making can take place amongst temporary staffing agencies. Moreover, we have illustrated how different types of temporary staffing agencies, including multinationals but also small independent agencies, can use specific tactics at the local level to develop new markets and create demand. Locally, it needs to be recognised that temporary staffing is a complex and 'messy' industry that incorporates a diverse range of ways in which individual behaviour is embodied in a broader framework of employment and recruitment and which can have significant impacts on the temporary staffing industry and the local labour market. Accounting for the social relations which underpin local labour markets and the temporary staffing industry in different places, and the ways in which these relationships interweave with wider national agreements, is an important aspect in developing a better understanding of the way the temporary staffing industry functions and how it affects local labour markets. Furthermore, being sensitive to the different and complex ways in which local relationships can socially regulate the temporary staffing industry is an important new insight from this research. 
Research on the insurgence of smaller locally operated agencies in the US during the mid to late 1990s pointed towards a downward pressure on margins and the destructive growth of the temporary staffing industry as smaller independent agencies sought to undercut their more established competitors (see Peck and Theodore, 2002). This meant that agencies were forced to resort to either cost-minimization forms of competition or 'share over margin' in order to drive competitors out of the market. Consequently, this often led to a price war at the level of the local labour market with all agencies locked into a cycle of cost cutting and margin trimming (ibid.). However, the research in Birmingham - and which we suggest has a wider applicability despite the particularities of the local labour market - identifies that competition amongst agencies at the level of the local labour market may result in such agencies developing more subtle and refined tactics of competition which go beyond cost cutting and margin trimming. The research found that agencies within the industrial and manufacturing sectors of the West Midlands had experienced severe decreases in margins to the point where lowering margins was no longer possible. Instead, agencies of different sizes were now using new tactics to allow them to compete locally and to find new ways of making markets for temporary agency labour. Given the market saturation identified in other areas beyond the UK, this finding has particular resonance.

In this context, the paper overall identifies two important issues that have received little attention hitherto in the existing literature, yet arguably demand further attention in respect of their relative nature and importance elsewhere. First, although it has been suggested that national agreements and neutral vendors mean that "local independent agencies lose business” (Ward, 2003a, 22) - and indeed this can be the case - by undertaking a very detailed examination of the temporary staffing industry and the relationships which develop at a local 
level between different actors, it is clear that the intricacies of these agreements are more complex than previously suggested. Indeed, it has been illustrated that in some cases local independent agencies can resist the loss of business. Second, the research conducted in Birmingham also highlights how the informal relationships which develop at a local level between agencies and (user) firms are not only actively re-shaping the temporary staffing industry locally, but that these relationships also have the ability to influence more formal wider agreements such as national agreements or master and neutral vendors. In addition, the research found that such informal relationships between temporary staffing agencies and clients have the ability to disrupt and reshape the temporary staffing industry: for example, the introduction of implementation teams by larger agencies focused on 'changing the hearts and minds of the end users' at the local level. Again, such issues require further exploration in the context of other places and different sectors in order to ascertain their importance. Finally, given the findings presented in this paper, a key message that emerges is it that there is a need for further research on the activities of temporary staffing agencies at the local level in order to consider new ways in which market making may manifest itself locally, as well as to further elucidate the role of the local temporary staffing industry within what Coe et al (2009a, 80) define as the "mosaic of distinctive national formations".

\section{Figure captions}

\section{Figure 1: Master Vendor / second-tier supplier relationship}

This shows the relationships between client firms, master vendor agencies and second tier agencies. 


\section{Figure 2: Neutral Vendor agreement}

This Figure shows the relationship between the client firm, the neutral vendor and temporary staffing agencies.

\section{Bibliography}

1. Befort, S., 2003. Revisiting the black hole of workplace regulation: a historical and comparative perspective of contingent work. Berkeley Journal of Employment and Labor Law, 24, pp.153-178.

2. Benner, C., Leete, L., Pastor, M. (2007) Staircases or treadmills?: Labor market intermediaries and economic opportunity in a changing economy. USA: Russell Sage Foundation.

3. Bergström, O. and Storrie, D., eds., 2003. Contingent employment in Europe and the United States. Cheltenham: Edward Elgar Publishing.

4. Birmingham City Council (2015) June 2015 Unemployment Briefing. Available at: www.birmingham.gov.uk/birminghameconomy

5. Bosanquet, N. and Doeringer, P., 1973. Is there a dual labour market in Great Britain? The Economic Journal, 83(330), pp.421-435.

6. CIETT (2012) The agency work industry around the world. Brussels: International Confederation of Temporary Work Businesses (CIETT) Economic Report.

7. Clarke, G., Gertler, M. and Whiteman, J., 1986. Regional Dynamics. Bostol: Allen and Unwin.

8. Coe, N., Johns, J., Ward, K. (2008) Flexibility in action: the temporary staffing industry and labour market restructuring in the Czech Republic and Poland. Environment and Planning A, 40: 1391-1415. 
9. Coe, N., Johns, J., Ward, K. (2009a) Agents of casualisation? The temporary staffing industry and labour market restructuring in Australia. Journal of Economic Geography, 9: 55-84.

10. Coe, N., Johns, J., Ward, K. (2009b) Managed flexibility: labour regulation, corporate strategies and market dynamics in the Swedish temporary staffing industry. European Urban and Regional Studies, 16: 65-85.

11. Coe, N., Johns, J., Ward, K. (2009c) The embedded transnational: the internationalisation strategies of the leading transnational temporary staffing agencies. GOTSU, The Geographies of Temporary Staffing Unit, University of Manchester, Working Paper No. 10.

12. Coe, N., Jones, K., Ward, K. (2010) The business of temporary staffing: a developing research agenda. Geography Compass, 4: 1055-1068.

13. Coe, N., Johns, J., Ward, K., (2011) Variegated global expansion: Internationalization strategies in the temporary staffing industry. Geoforum, 42: 61-70.

14. Doeringer, P. and Piore, M., 1971. Internal labour markets and Manpower analysis. London: M. E. Sharpe Publishers.

15. Fisher, L. (1951) The harvest labor market in California. The Quarterly Journal of Economics, 65: 463-491.

16. Forde, C. (2001) Temporary arrangements: the activities of employment agencies in the UK. Work, Employment and Society, 15: 631-644.

17. Gonos, G. (1997) The contest over "employer" status in the postwar United States: the case of temporary help firms. Law \& Society Review, 31: 81-110.

18. Gottfried, H., 1991. Mechanisms of control in the temporary help industry. Sociological Forum, 6(4), pp.699-713. 
19. Gottfried, H., 1992. In the margins: flexibility as a mode of regulation in the temporary help service industry. Work, Employment and Society, 6(3), pp.443-460.

20. Gottfried, H., Fasenfest, D. (2001) Temporary help in Southeastern Michigan: a segmented labour market and contingent geography. Wayne State University: College of Urban, Labor and Metropolitan Affairs, Working Paper Series Number 6.

21. Kalleberg, A., (2000) Non-standard employment relations: part-time, temporary and contract work. Annual Review of Sociology, 26: 341-365.

22. Kuptsch, C., ed. (2006) Merchants of labour. Geneva: International Institute for Labour Studies.

23. Lenz, E., 1996. Flexible employment: positive work strategies for the 21st century. Journal of Labour Research, 17(4), pp.555-566.

24. Massey, D., 1984. Spatial Divisions of Labor: Social Structures and the Geography of Production. New York: Routledge.

25. McDowell, L., Batnitzky, A., Dyer, S. (2008) Internationalization and the spaces of temporary labour: the global assembly of a local workforce. British Journal of Industrial Relations, 46: 750-770.

26. Moore, M. (1965). The temporary help service industry: Historical development, operation, and scope. Industrial and Labor Relations Review 18(4), pp. 554-569.

27. Nollen, S., 1996. Negative aspects of temporary employment. Journal of Labour Research, 17(4), pp.567-582.

28. Parker, R. (1994) Flesh peddlers and warm bodies: the temporary help industry and its workers. New Jersey: Rutgers University Press.

29. Peck, J. (1996) Workplace: the social regulation of labour markets. New York: The Gilford Press. 
30. Peck, J., Theodore, N. (1998) The business of contingent work: growth and restructuring in Chicago’s temporary employment industry. Work, Employment and Society, 12: 655-674.

31. Peck, J., Theodore, N. (2001) Contingent Chicago: restructuring the spaces of temporary labor. International Journal of Urban and Regional Research, 25: 471496.

32. Peck, J., Theodore, N. (2002) Temped out? Industry rhetoric, labour regulation, and economic restructuring in the temporary staffing business. Economic and Industrial Democracy, 23: 143-175.

33. Peck, J., Theodore, N., Ward. K. (2005) Constructing markets for temporary labour: employment liberalisation and the internationalisation of the staffing industry. Global Networks, 5: 3-26.

34. Purcell, J., Purcell, K., Tailby, S. (2004) Temporary work agencies: here today, gone tomorrow. British Journal of Industrial Relations, 42: 705-725.

35. REC (2011) Recruitment industry trends survey 2010/11. London: The Recruitment and employment Confederation (REC), Report.

36. REC, 2006. Recruitment industry census. London: The Recruitment and Employment Confederation (REC), Industry Research Unit.

37. Reich, M., Gordon, D. and Edwards, C., 1973. Dual labor markets: A theory of labor market segmentation. The American Economic Review, 63(2), pp.359-365.

38. REC, 2006. Recruitment industry census. London: The Recruitment and Employment Confederation (REC), Industry Research Unit.

39. Theodore, N., Peck, J. (2012) The Temporary Staffing Industry: Growth Imperatives and Limits to Contingency. Economic Geography, 78: 463-493. 
40. Van Breugel, G., Van Olffen, W., Olie, R. (2005) Temporary liaisons: the commitment of 'temps' towards their agencies. Journal of Management Studies, 42: 539-566.

41. Vosko, L., (2000) Temporary work: the gendered rise of a precarious employment relationship. Toronto: University of Toronto Press.

42. Ward, K. (2002) The UK temporary staffing industry: an overview. Manchester: British Academy and the University of Manchester, Report on the conduct of employment agencies and employment business regulations.

43. Ward, K. (2003a) Making 'flexible' Manchester: competition and change in the temporary staffing industry. GOTSU, The Geographies of Temporary Staffing Unit, University of Manchester, Working Paper No. 3.

44. Ward, K. (2003b) UK temporary staffing: industry structure and evolutionary dynamics. Environment and Planning A, 35: 889-907.

45. Ward, K. (2004) Going global? Internationalisation and diversification in the temporary staffing industry. Journal of Economic Geography, 4: 251-73.

46. Ward, K. (2005) Making Manchester 'flexible': competition and change in the temporary staffing industry. Geoforum, 36: 223-240. 